http://jmscr.igmpublication.org/home/

ISSN (e)-2347-176x ISSN (p) 2455-0450

crossref DOI: https://dx.doi.org/10.18535/jmscr/v8i5.54

\title{
Study of causes and contributing factors of infertility in couples attending a tertiary care centre
}

\author{
Authors \\ Dr Rajni Priyanka ${ }^{1 *}$, Dr Chitra Sinha ${ }^{2}$ \\ ${ }^{1}$ Senior Resident, Dept. of Obst \& Gynae, P.M.C.H, Patna \\ ${ }^{2}$ Associate Professor, Dept. of Obst \& Gynae, P.M.C.H, Patna \\ *Corresponding Author \\ Dr Rajni Priyanka \\ Senior Resident, Dept. of Obst \& Gynae, P.M.C.H, Patna, India
}

\begin{abstract}
Background: Infertility means inability to conceive after one year of regular unprotected intercourse. It is a global health issue with severe psychological effect on couples not having children.

Aim: To find out the clinical patterns and determinant of infertility in couples based on clinical and laboratory finding.

Methods: This is a prospective study carried out in department of Obstetrics and Gynecology of Patna Medical College Hospital, on Patients attending outdoor from January 2019 to December 2019. 300 Women were selected for the study with the diagnosis of infertility and 20 of them were lost to follow up so 280 women were enrolled in this study.

Result: The mean age of women in this study was $28.43 \pm 2.31$ years. Maximum women (62.14\%) were in age group 20-29 years. The median duration of marriage was 5 years (2-9 years). Primary infertility were reported in $172(61.42 \%)$ women and 108(38.57\%) women presented with secondary infertility. Female factor deficiency were found in $59.28 \%$ cases, $16.08 \%$ cases have only male factor, $24.64 \%$ having both male and female factor, whereas $15.24 \%$ cases are with unexplained infertility.

Features of polycystic ovaries and ovulatory dysfunction were found in $16 \%$ women. Adenexal pathology found in approx $10 \%$ cases, Uterine fibroid detected in $24(8.57 \%)$ cases and uterine anomaly were found in 10(3.57\%). In tubal factor pathology bilateral tubal blockade seen in 20(7.14\%) and single tube block were found in 40(14.28\%) women. $16.08 \%$ male had abnormality in semen examination. The common abnormalities were azoospermia (6.42\%) and oligozoospermiia in $4.64 \%$ cases.

Conclusion: Primary infertility cases are more common with female factor predominance over male factor. Ovulatory dysfunction, tubal pathology, hormonal imbalance and abnormal semen parameters were main contributing factor for infertility.

Keywords: Infertility, Female factor, Hysterosalpingography, Semen analysis.
\end{abstract}

\section{Introduction}

Infertility means inability to conceive after one year of regular unprotected intercourse. It is a global health issue with severe psychological effect on couples not having children affecting
$10-15 \%$ of couples ${ }^{1}$. Although the prevalence of infertility varies widely in different region. In developed countries the prevalence of infertility is $3.5-16.7 \%$ and in developing countries it is 6.9- $9.3 \%^{2}$. 
The difference in statistics of infertility and causes are diverse in different geographical region are mainly associated with reproductive behaviours and socio-cultural factors, such as age at marriage, educational status environmental condition, smoking and alcohol abuse, changes in lifestyle and diet ${ }^{3}$. In South Asia, infertility rate of approximately $10 \%$ was estimated on the basis of women studied at the end of their reproductive life in the age group (45-49 years) ${ }^{4}$.

There are various factors such as anatomical, physiological and genetic factor that causes infertility. Menstrual and ovulation dysfunction and uterine factors are the most common causes of impairment in fertility. About one quarter of female infertility is due to ovulatory dysfunction. A women ability to get pregnant can also be affected by age of the women which directly affect ovarian reserve. Hormonal conditions that can affect fertility include polycystic ovarian syndrome, thyroid problems, hyperprolactinemia, diabetes and premature ovarian failure. Tubal blockage or damaged tube, endometriosis, pelvic adhesions, fibroid uterus are major factor leading to infertility.

Many environmental and acquired factors also influence fertility .Smoking, drinking alcohol, using cocaine and other drugs directly affects fertility. Sexually transmitted diseases like Chlamydia and gonorrhoea also hamper fertility.

\section{Material \& Methods}

This is a prospective study conducted over a period of one year from January 2019 to December 2019 among the women attending outdoor of obstetrics and gynecology department of Patna Medical College Hospital, Patna, Bihar. A total of 3500 women were seen in the gynecology outdoor during the study period and approx 450 women were seen with complain of inability to conceive. The study sample included a total of 300 women with the diagnosis of infertility.

\section{Inclusion Criteria}

Women with complain of inability to conceive, whether its primary or secondary were included in this study.

300 women were selected with the diagnosis of infertility and 20 were lost to follow up so 280 women were enrolled in the study. The detail history of the couples were taken and clinical examination of female partner were done. Menstrual history was taken in detail, information regarding changes of puberty, galactorrhoea, sexual desire and frequency were asked The couple were counselled regarding all the relevant investigations. Blood samples were taken for hormonal assessment including thyroid function test and serum prolactin .Ultrasound was done to rule out any uterine or adenexal pathology initially, and for follicle monitoring to assess ovulation.

Hysterosalphingography (HSG) was done on day 8 to $10^{\text {th }}$ day of the menstrual cycle to see tubal patency and uterine cavity. Diagnostic laparoscopy with chromopertubation was done if any abnormalities were found in HSG.

For male partner history was taken regarding alcohol and drug abuse, testicular viral inflammation during puberty, any surgery in pelvic region like inguinal herniorrhaphy and sexually transmitted disease. Semen examination after three days of abstinence were done. Semen analysis was interpreted according to WHO guidelines and if any abnormalities were found, the male partner were referred to urologist for further assessment. Physical examination of testes in order to rule out varicocele or other lesion and hormonal assessment and ultrasound of tests were done according to the urologist advise.

\section{Result}

300 Women were selected for the study with the diagnosis of infertility and 20 of them were lost to follow up so 280 women were enrolled in this study. The incidence of infertility in our study is $12.85 \%$. 
Table -1: Socio-demographic features

\begin{tabular}{|l|c|}
\hline Variables & Number $=\mathbf{2 8 0}(\mathbf{\%})$ \\
\hline 1. Age(years) & $22(7.85 \%)$ \\
$<20$ & $174(62.14 \%)$ \\
$20-29$ & $66(23.57 \%)$ \\
$30-39$ & $18(6.42 \%)$ \\
$>40$ & \\
\hline Duration of marriage (years) & $130(46.42 \%)$ \\
$1-5$ & $60(21.42 \%)$ \\
$6-10$ & $44(15.71 \%)$ \\
$11-15$ & $46(16.42 \%)$ \\
$>15$ & \\
\hline Type of infertility & $172(61.42 \%)$ \\
Primary & $108(38.57 \%)$ \\
Secondary & $59.28 \%$ \\
\hline Female factor & $16.08 \%$ \\
Male factor & $24.64 \%$ \\
Both male and female factor & $15.24 \%$ \\
Unexplained & \\
\hline
\end{tabular}

The mean age of women in this study was $28.43 \pm 2.31$ years. Maximum women (62.14\%) were in age group 20-29 years, followed by $23.57 \%$ in age group 31-40years. The median duration of marriage was 5 years (2-9 years).Primary infertility were reported in 172 $(61.42 \%)$ women and 108(38.57\%) women presented with secondary infertility.

In this study, only female factor deficiency were found in $59.28 \%$ cases. $16.08 \%$ cases have only male factor, $24.64 \%$ having both male and female factor, whereas $15.24 \%$ cases are with unexplained infertility. Female factor are commonest factor for infertility in these studies

Table 2: Investigations of female partner

\begin{tabular}{|l|c|}
\hline \multicolumn{2}{|c|}{ Female factors } \\
\hline Ultrasonographic findings & Number (\%) \\
\hline Normal & $174(62.14$ \\
Polycystic ovaries \& Ovulatory dysfunction & $45(16.07 \%)$ \\
Ovarian cyst & $20(7.14 \%)$ \\
Endometriosis & $8(2.85 \%)$ \\
Fibroid & $24(8.57 \%)$ \\
Endometrial polyp & $14(5 \%)$ \\
Uterine anomaly & $10(3.57 \%)$ \\
Small uterus & $8(1.42 \%)$ \\
\hline Hysterosalphingography findings & Number $(\%)$ \\
\hline Bilateral patent tubes & $214(76.42 \%)$ \\
Single(right or left) tube block & $40(14.28 \%)$ \\
Bilateral tubal block & $20(7.14 \%)$ \\
Hydrosalpinx & $6(2.14 \%)$ \\
\hline Hormonal parameters & Number $(\%)$ \\
\hline & \\
\hline Hypothyroid ( TSH $\geq 4)$ & $27(19.28 \%)$ \\
Hyperprolactinemia $(\geq 25)$ & $15(10.71 \%)$ \\
FSH $\geq 10$ & $8(5.71 \%)$ \\
LH $\geq 10$ & $9(6.42 \%)$ \\
\hline
\end{tabular}

Ultrasonological findings were normal in 174(62.14\%) women, adenexal pathology found in approx $10 \%$ cases, features of polycystic ovaries and ovulatory dysfunction were found in $16 \%$ women.

Uterine fibroid detected in 24(8.57\%) cases .Uterine anomaly including bicornuate uterus, arcuate uterus were found in $10(3.57 \%)$ women and $4(1.42 \%)$ women presented with small uterus. Endometrial polyp were found in 5\% women.

In tubal factor pathology bilateral tubal blockade seen in 20(7.14\%) and single tube block were found in 40(14.28\%) women.

High level of $\mathrm{TSH}(\mathrm{TSH} \geq 4)$ were found in 27 $(19.28 \%)$ women and 15 women $(10.71 \%)$ diagnosed with hyperprolactinemia ( $\geq 25 \mathrm{ng} / \mathrm{ml}$ ). Approx $5.71 \%$ women were found to have high level of $\mathrm{FSH} \geq 10$, whereas $\mathrm{LH}$ was raised in $6.42 \%$ cases. FSH level more than $10 \mathrm{IU} / / \mathrm{L}$ is an indicator of ovarian resistance.

Table 3: Investigations of Male partner

\begin{tabular}{|l|c|}
\hline Male factor \\
\hline Semen analysis & Number (\%) \\
\hline Normal & $235(83.92 \%)$ \\
Azoospermia & $18(6.42 \%)$ \\
Oligospermia & $13(4.64 \%)$ \\
Asthenospermia & $14(5 \%)$ \\
\hline
\end{tabular}

Semen analysis is the primary investigation performed during male partner work up. 235 male $(83.92 \%)$ were. found with no abnormalities in semen parameter, only $16.08 \%$ male had abnormality in semen examination. The common abnormalities were azoospermia (6.42\%) and oligozoospermiia in $4.64 \%$ cases.

\section{Discussion}

Infertility is a major public health issue in many countries $^{5}$. The mean age of women in this study was $28.43 \pm 2.31$ years. Maximum women $(62.14 \%)$ were in age group 20-29 years, similar to a study ${ }^{6}$ in which maximum female infertile cases were in the age group 25- 29 years. The median duration of marriage was 5years (2-9 years). Similar findings were found in another stydy $^{7}$. Primary infertility were 
reported in $17261.42 \%$ ) women and $108(38.57 \%)$ women presented with secondary infertility which corresponds with a study done in western population in which primary infertility account for $60-70 \%$ cases $^{8}$.

In this study, only female factor deficiency were found in $59.28 \%$ cases. $16.08 \%$ cases have only male factor, $24.64 \%$ having both male and female factor, whereas $15.24 \%$ cases are with unexplained infertility. Female factor are commonest factor for infertility in these studies $^{9,10}$. The predominance of primary infertility $(61.42 \%)$ in our study coincides with the previous studies in which primary infertility is seen in almost $61-70 \%$ of cases and secondary infertility in $29-33 \%$ of patients ${ }^{8,11}$. Multiple etiological factors have been identified in female partner in this study. In tubal factor pathology bilateral tubal blockade seen in $20(7.14 \%)$ and single tube block were found in 40(14.28\%) women.

High level of TSH were found in $19.28 \%$ women and $10.71 \%$ diagnosed with hyperprolactinemia. Approx $5.71 \%$ women were found to have high level of $\mathrm{FSH} \geq 10$, whereas $\mathrm{LH}$ was raised in $6.42 \%$ cases. FSH level more than $10 \mathrm{IU} / / \mathrm{L}$ is an indicator of ovarian resistance and needed further investigations like antral follicle count and antimullerian hormone level. Women with tubal pathology were suggested with laproscopic evaluation. These parameters were not included in this study

In this study only $16.08 \%$ male had abnormality in semen examination. The common abnormalities were azoospermia (6.42\%) and oligozoospermiia in $4.64 \%$ cases. This result is similar to various studies in which azzospermia and oligozoospermia were common semen abnormalities $^{12,13}$.

In this study female factor is mainly responsible for infertility with various factors like ovulatory dysfunction, tubal pathology, uterine factor and hormonal disturbances.

\section{Conclusion}

Infertility is a major health issue affecting couple and need workout for both partners. Primary infertility was more common with predominance of female factor deficiency in this study. Ovulatory dysfunction is the main cause and tubal pathology, hormonal imbalance and abnormal semen parameters were other contributing factor.

Although both male and female factor are responsible, so counselling of both partner are necessary for a proper evaluation and to plan treatment according to the deficient factor. Simple treatment protocol should be followed before the aggressive infertility treatment like invitro fertilization.

Funding: No funding sources

Conflict of interest: None

\section{References}

1. Fritz MA, Speroff L, eds .Infertility .In: Clinical Gynecology Endocrinology and Infertility. $8^{\text {th }}$ ed. Philadelphia , USA: Lippincott Williams and Wilkins, Wolter Kluwer; 2011:1137-90 [Full Text Link]

2. Boivin J, Bunting L, Collins J, Nygren K. International estimates of infertility prevalence and treatment seeking : potential need and demamd for infertility medical care. Hum Reprod .2007;22 :1506-1512. [pubmed] [Google Scholar]

3. Macaluso M, Wright-Schnapp T, Chandra A, Johnson R, Satterwhote C, Pulwar A,et al .A public health focus on infertility prevention, detection, and management. Fertil Steril. 2010; 93:16 [pubmed][Google Scholar] .

4. Farely TMM, Baisey EM. The prevalence of a etiology of infertility .Proceedings, African Population Conference.28 November 1988; Senegal, Dakar;1998

5. Bello TO. Pattern of tubal pathology in infertile women on hysteron-salpingo- 
graphy in Ilorin, Nigeria. Annals of African Medicine 2004;3(2): 77-9.]

6. Sultana A, Tanira S, Adhikary S, Keya KA, Akhter $S$ Explained Infertility among the Couple Attending the Infertility Unit of Bangabandhu Sheikh Mujib Medical University (BSMMU), Bangladesh. J Dhaka Med Coll 2014;23 [1]; 114-20.[DOI]

7. Al -Turki HA. Prevalence of primary and secondary infertility from tertiary centre in Saudi Arabia. Middle East Fertil Soc J.2015 ;20:237-40.[DOI][ Science Direct ]

8. Templeton A, Fraser C, Thompson B. Infertility- epidermiology and referral practice. Hum Reprod .1991;6:1391-4.

9. Philippov OS, Radionchenko AA. Bolotova VP, Voronovskya NI, Potemkina $\mathrm{T} V$.Estimation of the prevalence and causes of infertility in Western Siberia. Bull World Health Organ. 1998:76(2):183-7.[Pub Med]

10. Anwar BR ,Fatima P, Afza N, Tarannum T, Begum N, Kulsum et al. Etiologic Factor of infertility in a referral Hospital (BSMMU, Bangladesh).J Med .2013;14(2):110-3[DOI]

11. Okonofua FE, Odunsi K .Infertility in Sub -Saharan Africa. Contemporary obstetrics and gynecology for developing countries. Publishers: Women"s Health and Action Reasearch Centre . Benin city. 2003 .p.128-56.

12. Chowdhury MA, Haque MM, Chowdhury S, Prodhania MS. Determinants of Infertility Among Couples Seeking Treatment in A Selected Clinic in Dhaka City. Chattagram Maa-O-Shishu Hosp Med Coll J .2014 ;13(3):42-5[DOI].

13. Pant PR .Factor affecting male infertility. Journal Inst Med.2009; 31(3): 10-2. 